\title{
Gunlög Fur
}

\section{Tillhör samerna den svenska historien?}

När jag i slutet av 1990-talet gjorde en inventering av svensk historisk forskning inför en artikel om kolonialism och historieskrivning fann jag endast tre historiker som skrivit avhandlingar om ämnen som berörde samer. Även i övrigt var det skralt när det gällde artiklar där historiker behandlat samisk historia. Översiktsverk behandlade inte heller samer - annat än högst marginellt - och när det gällde läromedel i skolans olika stadier kunde jag och andra konstatera att samerna nämndes i samband med geografi och religion, men inte i historia. ${ }^{1}$ Detta innebar naturligtvis inte att ingen kunskap fanns om samer i Sverige, men det antydde att samerna inte på något självklart sätt ansågs relevanta för berättelserna om den svenska nationens framväxt och förändring. Jag konstaterade då att det funnits "ytterst lite forskning och debatt kring Sverige som kolonialmakt eller som kolonial närvaro, kring de historiska frågor om äganderätt som blivit brännande i marktvisterna mellan samer och svenskar i Härjedalen och Jämtland, eller kring innebörden av medborgarskap och dess gränser i definitionen av begreppet same i början av seklet eller i samband med inrättandet av ett sameting på 1990-talet."’2

Sedan dess har förvisso mycket skett i en glädjande utveckling där allt fler projekt av olika slag behandlar samisk historia och sätter den i relation till svensk. Nätverk har etablerats, konferenser hållits och läromedel omarbetats. I grundskolans kursplan har kunskap om samer skrivits in även i ämnet historia. Undervisningen skall sträva mot att elever "tillägnar sig ett brett och djupt kunnande om kulturarvet, även såsom det utvecklats i olika nationella minoritetsgrupper, samt utvecklar insikt om den identitet som detta ger." ${ }^{3}$ Vidare fastställs att ämnet historia särskilt bör betona "den svenska och nordiska, inklusive den samiska, samt den europeiska kulturen." 4

För att detta ska vara möjligt är en förutsättning att det finns historieskrivning och utbildning att tillgå för blivande lärare i ämnet. Man kan man med fog ställa frågan om samerna tillhör den svenska historien och på vilket sätt. Har samiska individer, samhällen och kulturer en plats i berättelserna om nationens framväxt och formande? Handlar det utrymmet bara om underordning och förtryck? Finns det en egen samisk historia som är viktig att berätta, tolka och debattera också för icke-samer? Hur beskrivs kulturmöten i norr och vad har de haft för betydelse?

Historikern Harald Runblom genomförde under 2006 för Skolverkets räkning en undersökning av grundskolans och gymnasieskolans läromedel i historia och samhällskunskap med fokus på hur etnisk mångfald där behandlas. Slutsatsen är att behandlingen av samer i de allra flesta läroböcker är påver: "vanligen är presentationen så kortfattad att nyansering och problematisering är uteslutna." ${ }^{5}$ Runbloms rapport är knappast förvånande då samers historiska erfarenheter sällan diskuteras i forskning som berör Sveriges förflutna, vare sig det rör sig om översiktsverk eller specialstudier. Problemet kan formuleras som frånvaro, men lika ofta som bristande information om förhållanden på Nordkalotten. Det är inte ovanligt att när området nämns så beskrivs det som väglöst, "utan permanenta gränser". Oavsiktligt 
illustrerar sådana bisatser just hur lite samerna på allvar tänks ingå i den svenska - eller nordiska - nationella historien. Men Lappland, Finnmark och kusterna längs Norra Ishavet var knappast gränslösa, obebodda, eller obekanta för de människor som levde där långt innan gränskommissionen 1749 enades om att dela Sverige och Danmark-Norge längs kölen. Samerna kände resvägar, handelsrutter och bygränser långt innan dess, gränser som svenska myndighetsrepresentanter inte kunde ignorera utan konsekvenser. En stor del av svenska kronans norrlandspolitik gick till exempel ut på att förhindra att samerna flyttade över sin "renmakt", sin handel, och sina kunskaper till norska sidan av skandiska fjällryggen. Oro för att antagonisera samerna gjorde också att samiska önskemål och klagomål ofta tillgodosågs. Men läser man den svenska historia som kommer lärarstudenter till dels så får man lätt intrycket av att historien kommer till norra Norden först med nationalstaterna. ${ }^{6}$

Att samerna inte diskuteras i svensk historieskrivning kan också demonstreras på andra sätt. Ett är att titta på hur bibliotekens faktalitteratur klassificeras. Var hittar man böcker om samiska ting? Hur katalogiseras de? En mycket enkel undersökning genomförd på Jönköpings stadsbibliotek - som får anses välsorterat på dessa områden - gav följande resultat: där fanns påtagligt många fler träffar på sökordet “indianer” än på “samer". Ännu mer avslöjande var dock att majoriteten av titlarna om indianer var katalogiserade under bokstaven K (historia), följt av M (antropologi), medan de samiska titlarna nästan utan undantag fanns under M (antropologi) eller N (geografi). Litteratur vid två skolbibliotek i Växjö uppvisade ett liknande mönster: betydligt fler titlar om indianer än om samer. Men här framträdde också att böcker beträffande indianer generellt var av ett äldre datum än de om samer, samt att böcker om samer oftast behandlade samtida ämnen och konflikter som växer ur att leva i två världar, medan böcker om indianer oftare fokuserade historia och etnografiska detaljer från det förflutna. Likaså visade en genomgång av AV-media för skolor att medan det fanns ett liknande antal program rörande de två ursprungsfolken så fanns en klar skillnad i vad de behandlade. Filmer om indianer fokuserade historia, medan materialet om samer betonade den nutida situationen. Slutsatsen blir att samerna knappast finns i historien - i alla fall är den inte intressant att berätta. Och det ger knappast intryck av att de skulle ha en del i den svenska historien. ${ }^{7}$

Det är naturligtvis alldeles utmärkt att material om och av samer rörande samtida livsbetingelser och kultur finns att tillgå, men samtidigt visar det på stora utmaningar att foga samman det vi idag känner till om samisk-svenska relationer med de nationella berättelserna. Att det ser ut så här har att göra med gränsdragningarna mellan ämnen historia och antropologi. Ursprungsfolk, liksom "folken utanför Europa", utesluts ofta från ämnet historia under förevändning att studier av deras kulturer bäst görs av antropologin. 1965 skrev den välkände engelske historikern Hugh Trevor-Roper i sin studie The Rise of Christian Europe att när det gällde kontinenten Afrika fanns bara "the history of Europeans in Africa. The rest is largely darkness, like the history of pre-European, pre-Columbian America. And darkness is not a subject for history”. Trevor-Roper var varken särskilt inskränkt eller okunnig, utan ända fram till de allra sista årtiondena på 1900-talet skulle han nog fătt medhåll av de flesta andra historiker vid ärevördiga universitet. 1800-talets spektakulära frammarsch för europeisk teknologi, produktion och krigsmakt tycktes övertygande visa att här fanns världens centrum och att det var i efterhärmandet av detta samhälle som framtiden låg för den klotets majoritet 
som fortfarande befann sig i mörkret. Just denna industriella utveckling och koloniserande framgång innebar också att européer - och andra - kom att uppfatta Europa som den plats där genuin historisk utveckling skedde och detta var väldigt viktigt för hur historiedisciplinen kom att utformas, för den innebar strikta avgränsningar beträffande ämnesval och omfattning av historiska studier. Här kom Hegels formuleringar att spela en stor roll, då han menade att Medelhavsregionen var centrum för världshistorien och utan den kunde man inte tänka sig en historia om världen. Östasien ansåg han vara avskuret från den allmänna historiska processen och hade alltså ingen del i den. Afrika var ett barndomens land "som liggande bortom den medvetna historiens dag, är insvept i nattens mörka mantel". Som konsekvens av detta var inte Afrika en historisk del av världen, den hade ingen rörelse eller utveckling att visa upp. Inte heller när det gällde Amerika hade Hegel något gott att säga: "Amerika har alltid visat sig fysiskt och psykiskt maktlöst, och fortsätter att vara så”. Leopold von Ranke, som ofta beskrivs som den förste moderne historikern, fortsatte detta mönster och betonade särskilt nationalstaten som den främste aktören i historien. För Ranke var det Europa som utgjorde historiens kärnområde och nationalstaterna dess främsta aktörer och världshistoria handlade alltså om denna region. Alla andra delar av världen - de som saknade historia överläts åt antropologerna.

Både historia och antropologi fungerar genom att dra upp riktlinjer och matriser för vår uppfattning av tillvaron. Man skulle kunna se dessa ämnen som tidiga kolonisatörer som lägger under sig olika territorier. Historia behärskar då nationens territorium och upprätthåller strukturerna inåt genom att handla om "oss." Antropologin beforskar markerna utanför nationen och fokuserar "de andra" som objekt. Men båda bidrar till att stärka uppfattningen om den egna etniska och nationella gemenskapen som den naturliga historiska aktören. Jonathan Friedman menar att "anthropology is located at the defining edge of Western selfhood", medan historieskrivningen fungerar som ett redskap för att fördjupa gemenskapen mellan oss (inom nationen, folket eller regionen) genom att peka ut "de andra".

Sett i det ljuset blir inskrivning av samer i nordisk historia både en vetenskaplig utmaning och en politisk handling. Att göra det är att förutsätta att ursprungsfolk är berättigade, liksom andra medborgare, till historiska hänsynstaganden till frågor om äganderätt och kolonisation och till rätten att vara med om att definiera diskursen om det förflutna.

Det är också just i den moderna disciplinen historia som samerna osynliggjorts. För faktum är att samerna inte alltid varit frånvarande i svenska uppfattningar om det förflutna. För stormaktstidens krönikörer fyllde de en viktig roll i den historiska traditionen. I Erik Dahlbergs Svecia Antiqua et Hodierna (färdigställt posthumt 1716), vars monumentala syfte var "att sprida ljus och glans över fosterlandet i det förflutna och därigenom även i det närvarande" skymtar både samernas plats i framväxten av det svenska och roll i historien. Förhållandet mellan det "förflutna" och det "närvarande" dramatiseras i Dahlbergs bilder. Samerna och det samiska ges till exempel en framträdande roll i karaktäriseringen av grevskapet Lappland där vapnet med vildmannen omgärdas av detaljer som visar det samiska, som kåta, trumma, offerplats och skidor. Det är helt enkelt ett samiskt landskap som illustreras. Något annat kan ses i avbildningarna av de norrländska städerna. Dahlberg skiljer på de gamla och nya kuststäderna Piteå och Luleå och i dessa bilder framgår att samerna tillhör det förflutna landskapet, inte den närvarande staden. I den gamla tiden dominerar samerna och deras trans- 
portmedel älven och dess stränder, men i de nutida städerna har de fått ge vika för skepp och hästdragna vagnar. ${ }^{9}$ Lappmarksprästen Pehr Högström gav också en plats åt samerna i ett förflutet med betydelse för förståelsen av nuet. Genom att studera samernas levnadssätt kunde svenskar få en glimt av hur "wåra gamla förfäder Swear och Göthar äfwen fordomdags öfwer alt idkat." Såväl i Högströms resonemang som Dahlbergs bilder låg tanken om en utvecklingskedja förborgad, en tanke som kom att bryta fram i full kraft under de århundraden som följde. Idag är inte den tanken särskilt framträdande och vi talar inte om att studera det samiska samhället för att lära oss om "vårt” förflutna. Även om översiktsverken domineras av en linjär historiesyn så samerna försvunnit ur berättelsen - deras historia och den om deras interaktion med andra nordiska folk anses uppenbarligen inte relevant för förståelsen av hur Nuet blivit till, samtidigt som tanken att den skulle kunna ge kunskap om vårt förflutna känns lätt unken och rasistisk. Resultatet blir tystnad. Svensk eller nordisk historieskrivning är på den här punkten inte unik. ${ }^{10}$

Den kanadensiske pedagogen John Willinsky menar i boken Learning to divide the world att den stora tron på att utbildning ökar förståelsen och förenar i stor utsträckning är en myt. I stället fungerar utbildning, ända sedan man började med massutbildning - ungefär samtidigt med de stora imperiebyggandets tid i Europa- så att vi lär oss att dela upp världen och känna igen skillnader. Vi lär oss gränser och att urskilja specifika särdrag i olika länder och regioner, att skilja på Öst och Väst och att känna igen Första och Tredje världen. Konsekvensen blir att undervisningen gör att vi varseblir skillnader och att dessa sedan befästs. Genom historiestudierna kan då vissa nationers invånare få en upplevelse av värde och mening, medan de för andra bibringar befästandet av brist och maktlöshet. För många framstår historiens slut, eller förmågan att glömma det förflutna som den kanske enda framkomliga vägen till en mer jämlik och demokratisk framtid. Därför uppmanar oss Willinsky att kritiskt granska de böcker vi lär oss av och känna igen, när vi ser den, den imperialistiska historien om västvärldens framväxt. ${ }^{11}$ En slutsats efter läsning av Willinsky är att oavsett om Sverige deltog i jakten på koloniala territorier eller ej, så delar vi den kunskapssyn som ligger till grund för en imperialistisk historieskrivning.

Det är lätt att få för sig att det är i vår egen tid som vi förstår som mest och ser som klarast. Men låt oss gå tillbaka till 1700-talet igen. Tankar kring vilka som inkluderas och exkluderas i de nationella gemenskaperna är inte nya. Högström förklarar hur maktaspekter styr kategoriseringen i "vi och dom”. "Det är et gammalt fel hos oß”, skriver han, att vi gärna föraktar framsteg hos andra, hur stora de än må vara, när vi ställer dessa mot vad vi själva har "ehuru ringa det i sig sjelft är." Vi vet, skriver han, att andra folk har "underliga begrep" om vårt eget goda Sverige, på samma sätt som “wi om Lapmarken.” Och i en katten-på-råttan lek så sker "at hwad Ovidius skref om de Nordiska Länder i gemen, det lämpa utlänningarna på oß, men wi på Lapland." Men "lapparna” måste bära "alla sådana äretitlar...utan att hafwa någon ort norr om sig at skjuta skulden på." ${ }^{12}$ Etniska kollektiv skapas alltså i en process där det är viktigare att upprätthålla distans mellan det egna och det annorlunda än det specifika innehållet i denna skillnad. Detta urskiljande är nödvändigt för att upprätthålla hierarkier och för att det egna ska ges ett högre värde krävs makt att utse någon som kan fylla platsen som annorlunda. Samerna hade inte tillgång till vare sig det skrivna eller det tryckta ordet för att uttrycka sin uppfattning och hade heller inte någon annan ort att "skjuta skulden på." 
Oavsett hur tankemönstret såg ut på 1700-talet så kom sådana sätt att uppfatta ursprungsfolk att göra dem till historiens, det förflutnas, fångar. De utgjorde en spegelbild av vårt ursprung snarare än en aktiv del av nuet. Under inflytande av 1800-talets socialdarwinistiska tänkande cementerade detta uppfattningen av samer som del av ett mindre utvecklat stadium än den civilisation som svenskar var del av. Det är också under denna tid som samerna försvinner ur den svenska beskrivningen av nationens tillblivelse. Men tanken om ursprungsfolk som spegelbilder av ett för länge sedan passerat stadium levde kvar i antropologins skepnad och tog form i bilder som låste fast samerna i ett tidlöst etnografiskt då i vilket ingen förändring inträffar förrän européer inträder och sätter igång historiens rörelse genom att inlemma dem längst ner i ett hierarkiskt system.

Var kan då historia om samer höra hemma? Jag kan tänka mig flera fält inom historisk forskning där samiska berättelser och berättelser om samer behövs. För det första menar jag att samisk historia självklart bör ingå i den nationella svenska (eller norska, finska) politiska historieskrivningen, den som vi ofta kommer i kontakt med under skolgång och utbildning på olika nivåer. Samiska grupper och individer spelar med i de processer som format och formar nationen Sverige och dess relationer till omgivande makter och är i högsta grad närvarande aktörer i den postmoderna staten, inte minst som en region i det nya EU. Kronan och staten har på olika sätt i olika tider haft att förhålla sig till samer som distinkta grupper och lokala maktcentra, eller som undersåtar med behov och krav och det har bidragit till att påverka politiska beslut och handlingar såväl som nationell och regional självförståelse. ${ }^{13}$ Nära förbunden med den nationella politiska historien, men ändå väsensskild betraktar jag historien om möten och konflikter mellan samer, svenskar och andra folk och grupper. Kulturmöteshistoria utifrån etnohistoriska perspektiv som frilägger olika perspektiv och som ställer svensk och samisk historia i relation till andra koloniala möten runtom i världen ser jag som ett betydelsefullt och ännu till stor del obearbetat område. För att den ska bli fullödig behövs också en samisk historia som inte enbart relaterar till konungariket Sverige. Väsentlig är också en självständig samisk historieskrivning, utifrån en egen inre logik och rörelse, konflikter och kontakter, en där regionala och lokala förhållanden, likheter och skillnader, står i centrum.

Äldre historisk forskning talade om en integrering av den norra landsändan och samerna i resten av riket, en integrering som påbörjades under Gustav Vasa och sedan pågick i århundraden, åtminstone fram till dess att riksgränsen mellan Sverige och Danmark-Norge fastlagts vid mitten av 1700-talet. En betoning på integrering, eller inre kolonisation, leder till att forskningen fokuserar på likheter mellan samer och övriga undersåtar, framförallt då den svenska bondebefolkningen. Kolonisering och kolonialism får i detta perspektiv en betydelse av bebyggelse och odling, medan olikhet och skillnader i makt osynliggörs. Att tala om integrering gör också att det som sker i norr inte anses kunna jämföras med annan europeisk kolonisation av områden bebodda av ursprungsfolk, som t ex Nordamerika eller Nya Zealand. ${ }^{14}$ Att anlägga ett allmänt kolonialt raster som döljer all historisk specificitet i relationer på Nordkalotten är inget jag pläderar för, men den näst intill totala avsaknaden av akademisk forskning som anlägger ett kolonialt, eller postkolonialt, perspektiv på svensk-samisk interaktion gör att en sådan forskning kan erbjuda ett viktigt korrektiv och en utmaning till den förhärskande bilden av ett förhållandevis konfliktfritt inlemmande av en befolkning med ett 
annorlunda språk, religion, och världsuppfattning. Man bör åtminstone ställa sig frågan om denna uppfattning kunnat påverka den amnesi som gjort det möjligt för staten att tillvälla sig samiskt land genom svepande formuleringar och under inverkan av ett civilisatoriskt stadietänkande under 1800- och 1900-talen. Snarare än en integrering av samerna tycker jag att man kan tala om en distansering genom vilken en påtaglig samisk närvaro och inflytande under 1600- och 1700-talen förändras under senare århundraden så att samerna betraktas som mindre civiliserade och därmed blir statens skyddslingar, snarare än undersåtar. ${ }^{15}$

Samer har länge bemött de svenska pretensionerna på tolkningsföreträde när det gäller historia. Redan 1600- och 1700-talens skriftliga källor ger exempel på samisk historietolkning och historiska anspråk som jag menar att vi bör ta på allvar, särskilt i ljuset av resonemang om muntliga källor. När Pehr Högström beskrev samerna som ett demonstrationsexempel på svenskarnas ursprung så svarade samerna med en annan förståelse av det historiska skeendet:

På tilfrågan, om de wiste ifrån hwad ort deras förfäder kommit, och huru wida de woro med annat folk förbundne, har jag fătt til swar, det de gamle wetat säja, at Lappar och Swenskar warit i början et folk, och deras stamfäder woro kötslige Syskon, som hade haft samma fader och moder. Men det hände sig, at då et häftigt stormwäder opwäxte, blef den ena förskräkt, och sökte at förgöma sig under et bräde. Af hans efterkommande blefwo Swenskar, och gud lät detta brädet förwandlas til et hus. Men den andra, som war frimodigare och ej wille söka någon undanflykt, blef stamfar för Lappar, hwilka än idag hafwa sit tilhold så godt, som under bar himmel.

I detta citat, men också i många andra exempel från svenska källor av olika slag kan man skönja delar i en historisk tolkning som inbegriper att samerna en gång varit ägare av hela landet, att svenskarna med någon form av övervåld tagit det ifrån dem, att samerna är ovilliga att berätta för mycket om sin kultur och sina tolkningar för svenskar och att detta bland annat grundar sig i en stark önskan om att leva som sina förfäder, d v s att behålla sina egna traditioner och tolkningsramar. Det finns skäl att inte avfärda detta som skrönor eller myter - vilket några av deras samtida nedtecknare gjorde. Högström gjorde sig en hel del besvär att ta reda på vad samerna själva sade om olika ting rörande deras ursprung och ofta när han relaterar detta är det med hänvisning till "det de gamle wetat säja.” Det här torde på hans tid inte varit en hänvisning till att det var nonsens eller privata minnen, även om Högström klart satte det skriftliga före det muntliga. Men ännu i hans tid, eller i alla fall inte så långt innan, hade de arkiv som bevarats och traderats muntligt stor betydelse även i bondesamhället för att fastställa någots ursprung och förflutna förhållanden. Det vi gång på gång ser prov på, menar jag, i det äldre skriftliga materialet från lappmarkerna är att samer ser till att deras version av historiska händelser hamnar i dokumenten, de introducerar sin förståelse av samtid och förfluten tid i samtal, överenskommelser och konflikter. ${ }^{16}$

Den distansering och glömska som följt kräver nya verktyg för att dekonstrueras och det kan med fördel göras med etnohistoriska och postkoloniala perspektiv. Likaså är det relevant att jämföra med koloniala situationer i andra delar av världen. Clara Sue Kidwell och Alan Velie vid University of Oklahoma trycker på historiens centrala betydelse i sin programförklaring för Native American Studies. De framhåller vikten av att beskriva indianer som aktiva medskapare av skeenden och inte hjälplösa offer för historiska krafter - eller andra 
folk. Att de skulle varit passiva är en konsekvens av att de inte hade skriftspråk och därför nedtecknade sina versioner av det som skett. För att motverka denna obalans i källhänseende förespråkar de etnohistoriska metoder och beskriver dessa som en blandning av antropologins synkrona angreppssätt i studiet av kulturer som en specifik uppsättning beteenden, med historikers diakrona studier av förändring över tid. De betonar att kulturmöten mellan indianer och européer måste betraktas med utgångspunkt i båda sidors perspektiv och leda till ett erkännande av att indianska folk har sina egna och många gånger väldigt annorlunda berättelser om dessa möten. De menar vidare att en nyckel till förståelsen av kulturmöten är att det finns specifikt indianska uppfattningar om vad historia är. Muntliga berättelser och namn på platser är centrala delar i dessa unika perspektiv på det förflutna. Händelsecykler, alltså upprepning, är viktigare för den historiska förståelsen än linjära beskrivningar av unika händelser och förändring. ${ }^{17}$

Etnohistoria är en ännu inte särskilt vanlig metodologi i nordisk historisk forskning om samer. Men den tycks mig erbjuda en del viktiga redskap för en omtolkning av relationer mellan olika grupper i Norden. Etnohistoria syftar till att förändra historieskrivningens koloniala maktbalans genom en utvidgning av källbegreppet, ett tvärvetenskapligt angreppssätt och åtskillnad mellan etisk och emisk historieskrivning ( d v s en som utgår från utifrån- eller inifrånperspektiv). Kultur står i centrum för etnohistoriska studier, men inte som en fristående sfär, eller ideologisk överbyggnad, utan som den lins genom vilken forskaren kan urskilja olika förståelser och tolkningar av historiska skeenden. Likaså ger kulturen - i vid mening allt det som människor gör och tänker för att skapa mening kring sin tillvaro och sina livsuppehållande verksamheter - en kontext som möjliggör att också de som inte själva skrivit ner sin historia kan synas som aktörer och medskapare. Etnohistoriska metoder förutsätter en bred källsyn där skriftliga källor inte per automatik ses som överlägsna andra. Traditionella historiska källor bryts mot antropologiska studier, berättande källor, visuellt material, föremål. Det är också av stor vikt att forskaren söker att aktivt samarbeta med personer som kan lämna ingående information om såväl nutida kultur som om hur historien bevarats i muntlig tradering. Etnohistoriska perspektiv leder till att andra frågor kommer i fokus än de som dominerar en traditionell politisk eller ekonomisk historieskrivning. Tematik av betydelse kan röra frågor om ontologi, betydelsen av religion, att leva med en fot i två kulturer (gränsöverskridanden, skillnader inom kulturer), litteratur, musik, mytologi, historiska erfarenheter, vems perspektiv som dominerar, och ansvar. Men här ingår också frågor om vem som kan skriva denna historia, hur den ska skrivas och vad studieområdena har för relevans för dagens människor. Att bara skriva om det förflutna utan att koppla det till nuet, kan bidra till att dölja snarare än klargöra nutida problem. ${ }^{18}$

Etnohistoriska angreppssätt har mycket gemensamt med subalterna studier, som främst förespråkats av asiatiska forskare och det är relevant att anknyta till postkoloniala perspektiv. Dessa kännetecknas i hög grad av strävan att dekonstruera och heterogenisera centrum. Det är de koloniala projekten, med utgångspunkt i den europeiska geografiska expansionen, som står i centrum och fokus ligger på hur identiteter formas i relationer mellan det koloniala centrat och den koloniserade periferin, diskursiva praktikers betydelse för formeringen av "vit" identitet och "ras", diskussioner om dominans och hegemoni, analyser av ekonomisk, social och sexuell exploatering och av fysiskt och kulturellt våld. Världen är inbegripen $\mathrm{i}$ 
en och samma koloniala process där påverkan och förändring är ömsesidigt beroende om än assymetrisk. Att skapa skillnader (eller att betrakta skillnader som meningsskapande) tycks vara ett av kolonialismens tyngsta redskap, men det är ett vapen som slår tillbaka mot sig själv eftersom det aldrig lyckas att upprätta de rena och tydliga kategorier som åsyftas. Även om mångfald och ömsesidighet är honnörsord i det tidiga 2000-talets kulturdebatt så kan det vara vär att stanna upp inför hur historien undervisas i skolor och på universitet, hur läromedel framställer förflutna skeenden i synnerhet när det gäller historien om europeisk expansion. Man kan beskriva en kolonial kunskapssyn som styrd av binära par som skiljer på över- och underordning, kolonisatör och koloniserad, man och kvinna, vit och svart, centrum och periferi, väst och öst. Mot dessa anspråk kan ställas en postkolonial syn som strävar efter att dekonstruera dessa motsatspar. Betydelsebärande är i stället att analysera språk som en social praktik, att kritisera ideologier och kunskapsstrategier och att syna representationer. Robert Young har beskrivit att "det finns två typer av vita människor: de som aldrig befunnit sig i en situation där majoriteten av människor runt omkring dem inte är vita, och de som varit den enda vita personen i rummet. I det ögonblicket, för första gången kanske, inser de hur det verkligen är för andra folk i deras samhälle, och metaforiskt, för resten av världen utanför väst: att tillhöra en minoritet, leva som en person som alltid befinner sig i marginalen och som aldrig kan utgöra normen, den som inte har auktoritet att uttala sig." ${ }^{19}$ Utifrån denna erfarenhet har man talat om kunskapsproduktion (uppläggningen av universitetskurser, urval av litteratur, hur kronologiska samband upprättas och får makt att avgöra vad som är viktigt och inte $\mathrm{m} \mathrm{m}$ ), relationen mellan historia och antropologi (se ovan), nationens dominans som yta, subjekt och aktör i historien, kategorisering och differentiering, dikotomiernas betydelse och tyngd, hur kategorier upprättas, vidmakthålls och vad som utesluts. Makt är av stor vikt i postkoloniala resonemang, men betonar snarare de skiftande perspektiven och ömsesidig påverkan, samt det oförutsägbara i relationernas konsekvenser än en bestämd dominansordning mellan kolonisatör och koloniserad.

Det är dock viktigt att bära med sig att vetenskapliga perspektiv i sig inte erbjuder universallösningar. Inom ett kolonialt kunskapsparadigm kan rymmas både en glorifiering av kolonial expansion och en kritik som riktar in sig på Västerlandets skuld - och på att ställa den till rätta. Postkoloniala strömningar kan både ses som exponenter för vetenskapligt poststrukturalistiska riktningar, samt utgöra grund för en politisk retorik som knappast alls är "post"-relativistisk utan snarare tydligt normativ. Många menar att termen "post" kan få oss att tro att kolonialismen är över. Linda Tuhuwai Smith skriver att det bland forskare som kommer från ursprungsfolk finns "a sneaking suspicion that the fashion of post-colonialism has become a strategy for reinscribing or reauthorizing the privileges of non-indigenous academics because the field of 'post-colonial' discourse has been defined in ways which can still leave out indigenous peoples, our ways of knowing and our current concerns."'20

Kritiken bör mana till eftertänksamhet, men jag menar ändå att de ovannämnda angreppssätten skulle kunna inspirera forskning om samisk och svensk historia i både nya och gamla riktningar. Det är framförallt i jämförande perspektiv som jag ser att det finns tematiker som ännu saknas. Vi vet ännu endast lite om hur genus strukturerat mötet mellan samiskt och nordiskt och vilka konsekvenser det fătt för samhällen och individer, eller vad det betytt samer emellan. Mer kunskaper behövs om skillnader inom Sameland. Skola, utbildning, 
språkförbud och kulturkonfrontationer sedda och analyserade ur samiska perspektiv behövs det mer av. Likaså teoretiska och metodologiska studier som utmanar svensk historisk forskning. Varför behöver en svensk idag inte vara bunden av bilden av bonden (detta gäller förstås endast "etniska" svenskar och demonstrerar vad postkoloniala teoretiker menar när de talar om makt och omarkerade kategorier)? Svensken reser helt enkelt utan kulturellt bagage (eller möjligen bara handbagage), medan samer (och invandrare) drar omkring på en hel bagagevagn med tunga väskor fyllda med bilder av renskötare, kåtor, magi och annat. Vad sker med frågor om land när de kopplas till både metafysiska betydelser, materiella intressen och ideologier om hierarkiska ordningar?

Linné gjorde 1732 sin livs resa till Lappland. Där mötte han i mångt och mycket sitt paradis. "Är sommaren kortare än alla andra städes i världen, så tillstår jag ock, att han är angenämare," skrev han då och tillade: "Aldrig i mina dagar har jag levat friskare än nu." Men i detta, för svensken, väglösa land är han beroende av samiska vägvisare. I mötet med dessa blottas en annan verklighet. "Jag hade en vägvisare, som...ville ej obligera sig till att följa, förrän jag med värjan lovade stryk.” Så länge Linné höll värjan och tvingade mannen framför sig gick färden i riktning mot nästa granne på fjället, men så snart de kommit dit rusade vägvisaren iväg, "lämnande både pengar och avsked." ${ }^{21}$ I utrymmet mellan dessa bilder,

mellan det sunda livet $\mathrm{i}$ lappmarken och samers erfarenhet av svenska besökares tvång, finns en historia att berätta - en historia som i lika mån berör både samer och svenskar.

\section{Fotnoter}

1 Gunlög Fur, “Ädla vildar, grymma barbarer och postmoderna historier," Historisk Tidskrift 4, 1999: xx; Karin Granqvist Nutti, Samerna i svenska läroböcker 1868-1971, Umeå 1993.

2 Fur, "Ädla vildar,"

3 Skolverket (2000), s 76.

4 Skolverket (2000), s 77.

5 Harald Runblom, "En granskning av hur etnisk tillhörighet framställs i ett urval av läroböcker," Underlagsrapport till Skolverkets rapport I enlighet med skolans värdegrund?, s 46.

6 Harald Gustafsson och Hanne Sanders, red. Vid Gränsen, s 16; Lennart Lundmark, Samernas skatteland: Fur, Colonialism in the Margins; Gustafsson, Nordens historia; Lars-Ivar Hansen, Samenes historie.

7 Resultat från undersökningar gjorda av studenter vid kursen "Indianer och samer möter europeisk kolonisation” (HIB140:4) vid Växjö universitet åren 2001-2003.

8 Fur, "Ädla vildar;" Jonathan Friedman, "The Past in the Future: History and the Politics of Identity", American Anthropologist 94: 4 (1992), s 847.

9 Erik Dahlberg, Suecia Antiqua et Hodierna, (utg Stockholm 1924, med kort beskrivande text av Aron Rydfors); se också Fur, "Invandrare och samer" i Signums svenska kulturhistoria, Stormaktstiden.

10 Hodgen; Willinsky.

11 Willinsky, passim; Social Studies Research, s 119; 179.

12 Citaten från Pehr Högström, Beskrivning öfwer Sweriges Lapmarker 1747, (facsimile), Norrländska skrifter no 3 (Umeå 1980), ss. 11-12, 13, 37-38

13 Här börjar det finnas en hel del forskning som gör det möjligt att göra dessa kopplingar och visa på inflytande. Se t ex Lennart Lundmarks arbeten om lappskatteland; SoU 2006; Patrik Lantto;...För äldre tid se Lundmark; Fur; Hanna Hodacs om behovet av att distansera sig för att bekräfta civilisation.... 
14 Daniel Lindmark, "Utbildning och kolonialism. Svensk skolundervisning i Sápmi på 1700-talet," Tidskrift för lärarutbildning och forskning 3-4, 2004: 13-14.

15 Lundmark talar om statens glömska kring 1800. Under inflytande av detta antal olika ekonomiska, politiska, och idemässiga faktorer glöms samernas särställning bort vid denna tid och leder till ett tydligt brott i samiska rättigheter till mark och vatten...

16 Fler exempel, från Fur, Colonialism...

17 Clara Sue Kidwell and Alan Velie, Native American Studies, 11-14, 41.

18 Se tex Will Roscoe, Changing Ones. Third and Fourth Genders in Native North America, New York: St. Martin's Press, 1998: s 19-20; Mihesuah, ed...

19 Robert Young, Postcolonialism. A Very Short Introduction, 2003: s

20 Linda Tuhiwai Smith, Decolonizing Methodologies. Research and Indigenous Peoples, London and New York: Zed Books Ltd, 1999, s. 24.

21 Carl Linnaeus, Lapplandsresa Ar 1732, red. av Magnus von Platen och Carl-Otto von Sydow, Wahlström \& Widstrand, 1975, ss. 95, 137. 